\title{
Solubility of Sulfur in Rubber
}

\author{
By C. S. Venable and C. D. Greene
}

Research Laboratory of Applied Chemistry, Massachusetts Institute of Technology, Cambridge, Massachusetts

The degree of solubility of free sulfur in rubber under various conditions has a practical as well as a theoretical interest. For example, this solubility is one of the two determining factors in the well-known phenomenon of "blooming." The presence of an excess of free sulfur unquestionably plays an important role in the aging of rubber goods. Furthermore, a number of theories as to the mechanism of vulcanization presuppose as the first step the melting of the sulfur and its solution in the rubber, and involve a difference in solubility of free sulfur as vulcanization proceeds.

The following paper records preliminary work on this important subject. The solubility of sulfur in rubber apparently increases slowly with the vulcanization coefficient, more rapidly as the temperature increases. With a coefficient greater than 7 per cent combined sulfur, solubility values could not be obtained by the method used because the rubber became almost impermeable to free sulfur. This impermeability probably has much more to do with the nonblooming of hard rubber stocks than has the slightly increased solubility for free sulfur.

I $T$ spite of the importance of the subject, no quantitative data have been published on the solubility of sulfur in rubber. Practically the only results recorded are those of Skellon, ${ }^{3}$ who placed together thin sheets of rubber containing different amounts of rubber and heated them to the vulcanization temperature. By analyzing for free sulfur he determined in which direction the sulfur had migrated. Obviously, he could thus obtain only approximate limits for sulfur solubility. The maximum solubility at $130^{\circ}$ to $140^{\circ}$ was apparently at about 10 per cent sulfur, and the solubility increased with the degree of vulcanization, a point of view which has often been taken in explaining the non-blooming of hard rubber. Skellon did show that the sulfur distributed itself fairly rapidly through the rubber in all directions. It is, of course, known that the solubility decreases as the temperature is lowered.

In order to secure more definite information, the following investigation was carried out in connection with some cooperative work for the Goodyear Tire and Rubber Company and is now published with their permission. The experimental determination of these solubility figures was a rather difficult problem. Even the best procedure which this Laboratory was able to develop did not give satisfactory results at any temperature for values of combined sulfur exceeding 7 per cent, and there is some doubt about several points obtained at the lower temperatures for values of combined sulfur less than 7 per cent. The results must therefore be considered as preliminary, but their publication seems desirable in view of the existing lack of information.

\section{Procedure}

The method adopted was to pack in flowers of sulfur thin strips of rubber stock that had been compounded with different amounts of sulfur ( 0 to 20 per cent on the weight of rubber used), and to keep the pack at the desired temperature until equilibrium was established between strip and sulfur. The samples were then analyzed for free and combined sulfur.

1 Presented before the Division of Rubber Chemistry at the 62nd Meeting of the American Chemical Society, New York, N. Y., September 6 to 10,1921 .

2 Published as Contribution No. 44 from the Research Laboratory of Applied Chemistry, M. I. T.

${ }^{8}$ Kolloid $Z$., 14 (1914), 96.
Equilibrium was approached from above and below, that is, from an excess and a deficiency of original free sulfur. If the sample contained a deficiency of free sulfur, sulfur migrated in and equilibrium was fairly quickly established. On the other hand, if the original sample possessed a large excess of free sulfur, usually present as crystals within the rubber, little if any of the excess sulfur migrated to the outside of the sheet. Consequently, all samples were given a preliminary heating at $120^{\circ} \mathrm{C}$. to insure complete solution of the crystals before placing in the pack. It is common

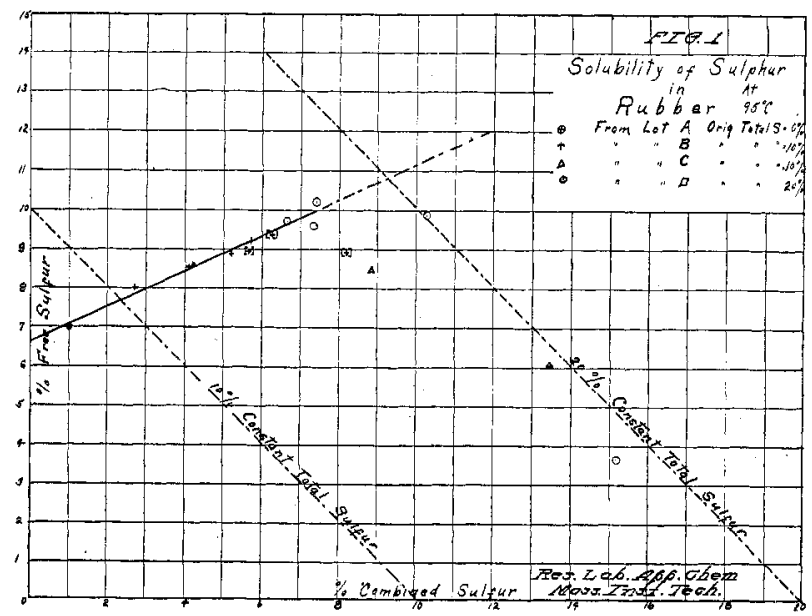

experience that, in the absence of crystallization centers within the rubber, a supersaturated solution forms, and the excess sulfur tends to migrate to the outside until equilibrium is approached. This short heating at $120^{\circ}$ was repeated when the sample had apparently reached equilibrium to make sure that no crystallization centers had re-formed while the rubber was in the pack. In either case, the equilibrium point was determined either by a constancy in weight of sample after short intervals of heating, or better still by a practical constancy in values of free sulfur upon analysis. of the samples from time to time.

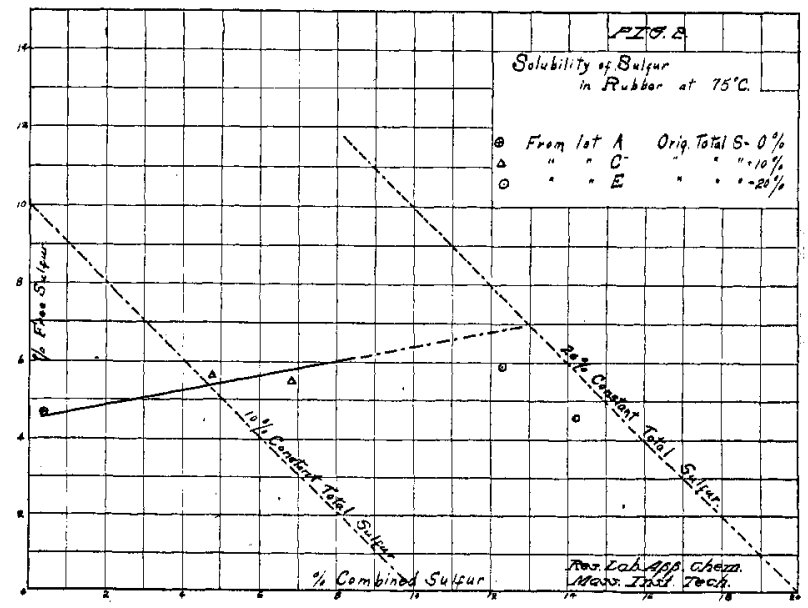

It should be emphasized that the quantities of free sulfur found by the above procedure should represent the amount. held in solution by the rubber in equilibrium with solid sulfur 
at the same temperature; in other words, the true solubility of sulfur in rubber.

\section{Analtitical Methods}

The following analytical procedures were adopted:

FREE SULFUR-The method used was essentially that developed by W. J. Kelly ${ }^{4}$ of the Goodyear Company.

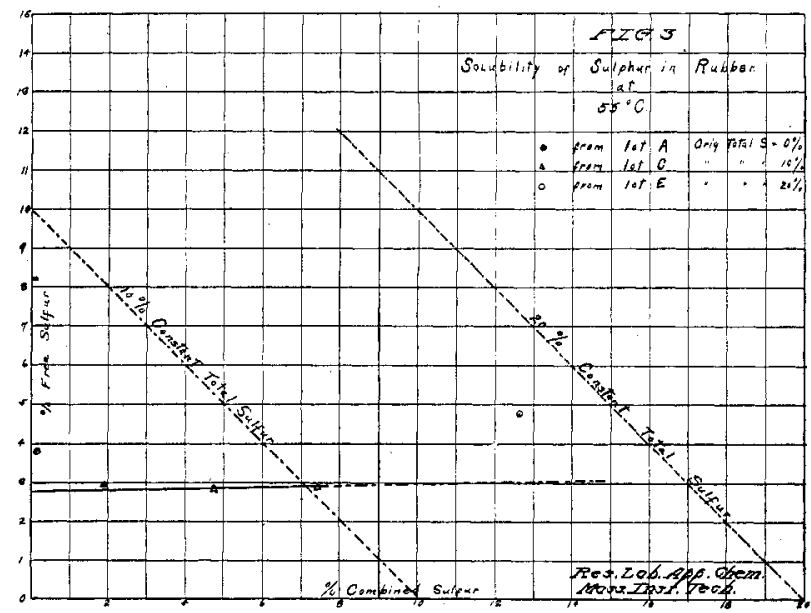

The acetone solution obtained by a 16-hr. extraction of the sample was evaporated to a sirupy consistency and extracted with 75 per cent alcohol (saturated with sulfur) to remove resins and acetone-soluble sulfides. The residual sulfur was freed from alcohol, oxidized with bromine-carbon tetrachloride and zinc oxide-nitrio acid solutions, and weighed as barium sulfate.

COMBINED SULFUR-The residue from acetone extraction was refluxed for $8 \mathrm{hrs}$. with alcoholic sodium hydroxide to remove any acetone-insoluble sulfur compounds other than polyprene sulfide. If zinc oxide had been present in the original samples, the residue was repeatedly evaporated with dilute hydrochloric acid until evolution of hydrogen sulfide had ceased. The final residue was oxidized with zinc oxidenitric acid and bromine-nitric acid, and the sulfur was weighed as barium sulfate.

All results are reported in grams of sulfur per $100 \mathrm{~g}$. rubber.

\section{SAMPLES Used}

The rubber used was smoked sheet, in strips about $1 \mathrm{~mm}$. thick and compounded by weight as follows:

\begin{tabular}{|c|c|}
\hline LоT No. & DESCRIPTION \\
\hline A & Smoked sheet, unvulcanized \\
\hline B & $\begin{array}{l}\text { Smoked sheet, } 100 ; \text { sulfur, } \\
10 ; \text { thiocarbanilide, } 3\end{array}$ \\
\hline $\mathrm{C}$ & $\begin{array}{l}\text { Smoked sheet, } 100 \text {; sulfur, } \\
10 ; \text { zinc oxide, } 10 \text {; thio- } \\
\text { carbanilide, } 3\end{array}$ \\
\hline $\mathrm{D}$ & $\begin{array}{l}\text { Smoked sheet, } 100 ; \text { sulfur, } \\
20 ; \text { thiocarbanilide, } 3\end{array}$ \\
\hline $\mathrm{E}$ & $\begin{array}{l}\text { Smoked sheet, } 100 ; \text { sulfur, } 20 \text {; } \\
\text { zinc oxide, } 10 \text {; thiocarban- } \\
\text { ilide, } 5\end{array}$ \\
\hline
\end{tabular}

Samples B, C, D, and $\mathbf{E}$ were vulcanized to coefficients varying from 1 to 8 per cent combined sulfur before placing in the sulfur pack. For a given solubility determination, a sample was chosen with a vulcanization coefficient close to that desired.

\section{EXPERIMENTAL RESULTS}

In Figs. 1 to 3 are plotted values found for free sulfur (sulfur in solution) against vulcanization coefficient at $95^{\circ}$, $75^{\circ}$, and $55^{\circ}$, respectively. Inasmuch as these values were approached from an original total sulfur content of 0,10 ,

- This Journal, 14 (1922), 196. or 20 per cent, lines have been drawn on each diagram for 10 per cent and 20 per cent total sulfur contents. In other words, these lines show how the free sulfur would have varied with the degree of vulcanization had there been no diffusion of sulfur into or out of the sample.

SoldBILITY AT $95^{\circ} \mathrm{C}$.-At $95^{\circ}$ the solubility curve appears to be a straight line function of the amount of combined

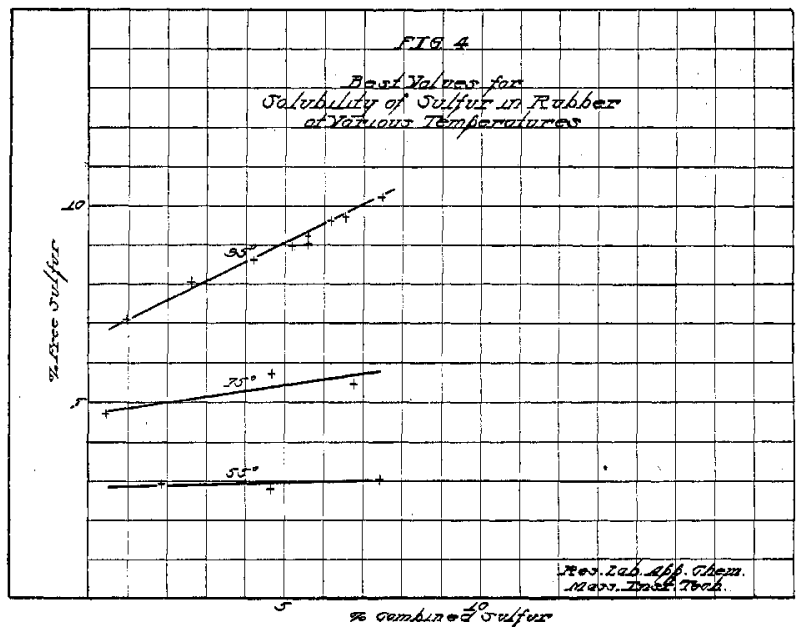

sulfur, up to a vulcanization coefficient of about 7 per cent. At this point the curve breaks. No reliable data could be obtained for the harder stocks. Apparently, the migration of sulfur in either direction is markedly. retarded by the increasing hardness of the stock. This is indicated by the fact that total sulfur becomes nearly constant. For example, the bracketed points represent successive determinations made on a sample from Lot B after different intervals of heating. The points oorresponding to a combined sulfur content of 5.7 and 6.3 per cent follow closely the solubility line. However, the point corresponding to a combined sulfur content of 8.2 per cent drops along a line of constant total sulfur content. In general, for a stock with a combined sulfur content exceeding 7 per cent, it was found impossible to check free sulfur values by using stocks containing different amounts of total sulfur, as was done with stocks vulcanized to a combined sulfur content of less than 7 per cent.

solUBILITY AT $75^{\circ} \mathrm{C}$.-The solubility curve at $75^{\circ} \mathrm{C}$. was determined from a smaller number of points, but the same relationship apparently holds. The solubility is apparently

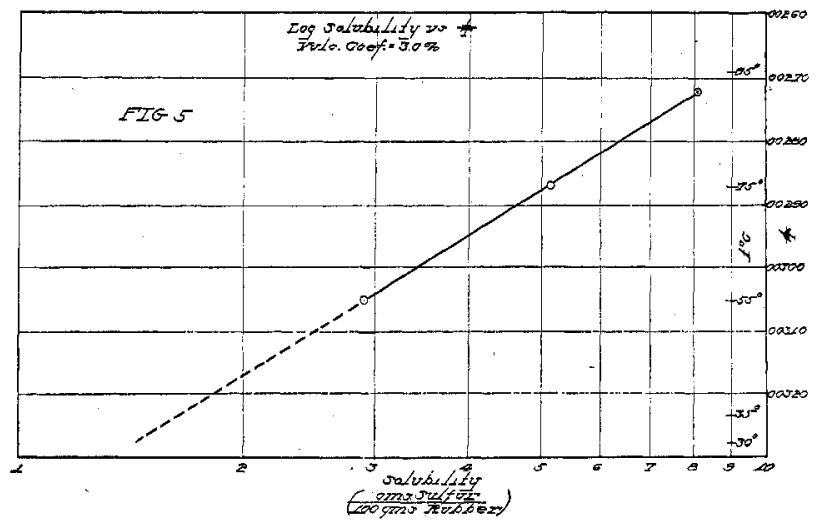

a straight line function up to a combined sulfur content of about 7 per cent. Beyond this point, migration of sulfur is apparently retarded, and no reliable data were obtained.

SOLUBILITY AT $55^{\circ} \mathrm{C}$. - It was thought that the time required to reach equilibrium at this temperature might be decreased by heating the samples in sulfur at $95^{\circ} \mathrm{C}$. for 4 